Running head: Mental toughness

\title{
Mental Toughness: Progress and Prospects
}

\author{
Daniel F. Gucciardi \\ School of Physiotherapy and Exercise Science, Curtin University
}

Author Notes

Address correspondence to Daniel Gucciardi, School of Physiotherapy and Exercise Science, Curtin University, GPO Box U1987, Perth, Australia, 6845. Email: daniel.f.gucciardi@gmail.com

Funding statement. Daniel Gucciardi is supported by a Curtin Research Fellowship. 


\section{Abstract}

2 Mental toughness (MT) has become a popular area of investigation and practice within sport

3 and exercise psychology over the past two decades. Since the turn of the twenty first century,

4 there have been hundreds of studies published on mental toughness, yet concerns remain

5 about the conceptualization and measurement of mental toughness. In this paper, I take stock

6 of past work with the goal of clarifying and elaborating the most fundamental and common

7 aspects of MT. I also look to the future and outline key substantive and methodological issues

8 that may offer the greatest potential for refining the conceptualisation of MT and contributing

9 to theory building on this concept. My hope is that this information will provide a platform

10 from which to foster coherent and systematic scholarly work on MT. 


\section{Mental Toughness: Progress and Prospects}

In contexts where high performance underpins innovation, competitive advantage and success, there are few constructs that resonate as deeply with people as that of mental toughness (MT). The concept of MT has captured the attention of both researchers and practitioners alike, with an explosion of research and heightened interest among practitioners and coaches over the past two decades. Unsurprisingly, MT has become one of the most prevalent concepts within the broader field of positive psychology [1]. Given this research activity, it is reasonable to assume that we have learned a great deal about MT. The purpose of this paper is to consider this assumption, with the view to uncover what is currently known about MT and what remains to be learned.

\section{Taking Stock}

The conceptualisation and definition of MT has been problematic since the term was first introduced within the popular press [2,3] and academic literature [4,5]. Despite the wealth of research that has been conducted over the past two decades, there remains confusion and disagreement regarding the meaning, distinctiveness, and usefulness of MT for theory and practice in sport and exercise settings. These conceptual concerns have provided the foundation for several authors to challenge the legitimacy of MT as a scientific construct $[6,7]$. However, it seems premature to throw the baby out with the bathwater until these conceptual issues have been subject to critical analysis and debate. In this section, I take stock of past work with the goal of clarifying and elaborating the most fundamental and common aspects of MT.

Meaning of MT. Much has been written about the conceptualisation and definition of MT to the extent that numerous definitions have been proposed. A chronology of primary definitions of MT is provided in Table 1. Although these definitions share similarities, especially in terms of the entity to which MT applies (person) and the general property of the 
construct (psychological resource that is salient for challenging or stressful circumstances), they also differ in two key respects. First, whereas early work defined MT in relation to one's opponents [5], recent research has broadened this conceptual theme to encompass subjective or goal-directed dimensions [15]. This conceptual shift represents an important clarification in response to criticisms of MT [6,7]. For example, a first year player on the professional tennis circuit who is competing against a top-ranked, seasoned campaigner (think of Roger Federer, Rafael Nadal, Novak Djokovic) is unlikely to beat his opponent (i.e., win/loss). However, it is likely that the rookie has set specific goals to achieve during his competition against this top-ranked player (e.g., achieve a certain $\%$ of successful first serves, forehand winners) and it is these self-referenced targets that provide meaningful information in terms of making inferences regarding his degree of MT. Second, the degree of specificity with regard to the conceptual theme of MT has ranged from highly specific [8] to broad categories of fundamental attributes or defining characteristics [10]. Put simply, scholars differ on whether they take a narrow or broad view of the content space of MT. Given the variety of definitions and conceptual discrepancies between them, some scholars have questioned the likelihood of defining MT in a concise and unambiguous way [6].

The problems associated with poor conceptual clarity are well known and include confusion regarding what is and is not encapsulated by the construct; its distinctiveness with existing constructs; deficient or contaminated indicators of the construct; and invalid conclusions regarding the role of the construct as an antecedent, mediator, moderator, or outcome variable $[16,17]$. An inspection of Table 1 reveals several limitations with current definitions of MT including those proposed by my colleagues and me. First, MT has been defined in terms of its unique characteristics or features rather than the commonality among these individual attributes [8], which excludes other potentially relevant qualities that reflect those features that tie them together. Second, several definitions encompass outcomes of MT 
to define the nature of the concept [e.g., 5,10], which conflates two separate aspects of theory development and is therefore impossible to test empirically [16]. Disentangling a concept from its determinants and outcomes is important for theory development; for example, one's degree of MT is different from how it is fostered (i.e., antecedents) and what it enables one to do (i.e., outcomes). The imprecision and ambiguity of existing definitions thwart coherent and systematic scholarly work and spark questions regarding the usefulness of MT as a scientific concept.

An updated conceptualisation of MT. In taking stock of past work, and guided by recommendations for generating clear concept definitions of psychological phenomena [18], I propose an updated working definition of MT. Given the conceptual complexities inherent within past work, my goal here is to clarify and elaborate the most fundamental and common aspects rather than resolve the definitional problems of MT. Specifically, MT can be defined as a state-like psychological resource that is purposeful, flexible, and efficient in nature for the enactment and maintenance of goal-directed pursuits. This definition provides an important first step in fulfilling several expectations for construct clarity [17-19], and addressing past criticisms of MT (e.g., absolutist language; [6]). First, the general type of property to which MT refers is a psychological resource that is contextualised within goaldirected pursuits during which individuals experience a range of challenging or stressful circumstances. In this sense, MT does not encompass observable behaviours, which instead represent important outcomes of the construct [20]. Second, MT applies to people, which is distinct from other types of entities such as a process, outcome, task, relationship or culture. Third, conceptualised as a resource, MT is positioned within a broader category of concepts "that either are centrally valued in their own right (e.g., self-esteem, close attachments, health, and inner peace) or act as a means to obtain centrally valued ends (e.g., money, social support, and credit)" [21, p. 307). Of particular relevance are three key contextual conditions 
87 that help distinguish MT from other resources: (i) state-like implies the characterisation of

enduring yet varying properties across situations or time $[5,15]$ and which are open to development or change [22]; (ii) psychological limits the content universe to skills, knowledge, or attributes that are inherent aspects of a person's make-up; and (iii) to be considered an exemplar of MT, psychological dimensions should be purposeful (i.e., provide direction and energy towards self-referenced objectives), efficient (i.e., maximise the congruence between displayed behaviour and self-referenced objectives), and flexible (i.e., flexibility to competing goals, novelty, change and uncertainty) in nature [22-25]. Finally, conceptualised as a resource caravan [15], MT represents a unidimensional concept where psychological dimensions accumulate and integrate over time [21] because they share the commonality of purpose, adaptability, and efficiency. Although past qualitative work (e.g., $[5,11,26])$ and operationalisations of MT via self-report questionnaires (e.g., $[8,12])$ suggest a multidimensional perspective, recent evidence indicates that participants do not make such subtle conceptual distinctions between unique psychological dimensions [15,27].

Distinctiveness of MT. Distinguishing MT from related constructs is important for conceptual clarity and therefore its scientific legitimacy, yet there has been little effort directed toward this critical aspect of concept development. A primary concern in this respect is that the most widely employed framework of MT and its associated measure - the $4 \mathrm{Cs}$ model and MTQ48 [8] - borrows heavily from the related construct of psychological hardiness. The conceptualisation of hardiness has evolved from a personality disposition underpinned by a core set of attitudes or beliefs that buffer the effects of stress [28] to one that provides an existential courage to transform experiences of stress and adversity into opportunities for growth and development [29,30]. Of particular relevance to hardiness are the dimensions of challenge, commitment, and control; that is, accepting stress and adversity as a normal part of life and being important for growth and development (challenge), staying 
involved in stressful circumstances because they are meaningful experiences (commitment), and remaining agentic in one's experiences so as to influence outcomes [31]. Meta-analytic evidence drawn from correlational research supports the protective nature of hardiness on the ill-effects of stress on performance and health [32].

Within the context of the 4Cs model [8], the three facets of hardiness - control, commitment and challenge - are combined with the construct of confidence to form MT. The addition of confidence to the $3 \mathrm{Cs}$ of hardiness was considered essential to integrating theory with practice (e.g., salience of competition) for MT conceptualisation [8] and is supported by subsequent research $[5,10]$. However, there has been little theoretical justification for the distinctiveness of the $4 \mathrm{Cs}$ model thus blurring the conceptual boundaries with hardiness. For example, what are the necessary and sufficient attributes of MT that justify the integration of confidence with control, commitment and challenge, yet exclude other constructs (e.g., flexibility)? As such, it remains unknown whether the 4Cs model of MT is a distinct concept, or an extension of hardiness. Added to this conceptual ambiguity is the unavailability of empirical data to support the incremental validity of the 4Cs model of MT with regard to hardiness, which is important for the acceptance of new constructs and measures within scientific and practical settings [33]. There are also psychometric concerns regarding the operationalisation of the 4Cs model of MT via the MTQ48 [34,35]. For these conceptual and empirical reasons, how or why the 4Cs model represents a unique and valid conceptualisation of MT remains unclear.

The updated definition of MT presented here provides a platform from which to consider its distinctiveness from related constructs. Resilience is one construct that is used interchangeably with MT. Broadly defined, resilience refers to "the capacity of a dynamic system to adapt successfully to disturbances that threaten its function, viability, or development" [36, p. 10]. Although resilience and MT share the common thread of 
adaptability to stressful experiences, they also differ in three respects. First, MT is confined to discussions regarding psychological resources of people, whereas resilience can apply to a range of systems such as individuals, groups, organisations, economies, and ecosystems.

Second, within the context of resilience, one's capacity for adaptation is underpinned by a range of protective factors including individual (e.g., biological factors), community (e.g., social support), and societal (e.g., health and social services) dimensions [37]. In contrast, MT is concerned solely with psychological resources of the individual, and therefore represents one of several broad types of protective factors for resilience. Third, as defined resilience is a largely reactive concept in that one's capacity for adaptability is most salient when confronted with stressors or adversity; of course, this capacity may be useful for proactive endeavours, yet to study resilience in ways that are useful for advancing theory, it is essential to delineate and measure functioning (e.g., health) both before and after an adversity [38]. In contrast, MT is most salient for goal-directed endeavours that encompass both proactive (e.g., planning for competition) and reactive (e.g., dealing with injury) experiences which encompass stressors of varying intensity, duration and frequency.

Given the goal-directed nature of MT, it is also important to distinguish this concept from grit. Grit, which is defined as the disposition to pursue long-term goals with "passion and perseverance” [39, pp. 1087-1088], is conceptualised as a facet of Big Five conscientiousness and involves working hard and diligently over long periods of time towards superordinate goals [40]. Although MT and grit share the commonality of being purposeful and perseverant in nature [41], they differ in two respects. First, grit is conceptualised as dispositional in nature and therefore reflects consistencies in people's passion and perseverance towards a singular long-term goal across situations, contexts and time $[42,434]$. In contrast, as MT varies within individuals across situations and over time [15], it best represents a state-like concept that has properties that endure yet can also 
162 fluctuate depending on the goal or objective. Second, grit and MT differ with regard to the scope of the goal; grit is concerned primarily with a singular objective or superordinate goal (e.g., make the Olympic team) and its corresponding lower-level targets and processes [44], whereas MT is salient for goal-directed pursuits that encompass multiple and potentially conflicting superordinate goals (e.g., make the Olympic versus prepare for a career after sport) $[10,14]$.

Usefulness of MT. One of the primary criticisms of MT research [6] - and more broadly the sport and exercise psychology literature [45] - is the reliance on arbitrary metrics. A metric is considered arbitrary "when it is not known where a given score locates an individual on the underlying psychological dimension or how a one-unit change on the observed score reflects the magnitude of change on the underlying dimension" [46, p. 28]. Although correlations between one arbitrary metric and another (e.g., self-reported MT and stressor appraisals) are an important component of validation work, they provide little information regarding the usefulness of a construct in terms of real-world behaviours. Cognisant of this methodological limitation, researchers have examined the associations between MT and objective indicators of performance outcomes in recent years. Within sporting contexts, self-reported [41,47] and experimentally induced increases in MT [22] have been positively associated with performance in competitive and lab-based settings. The positive association between MT and performance observed with athletes has generalised to military samples $[15,48]$. Collectively, these findings provide preliminary support for the usefulness of MT.

\section{Considering New Horizons}

Sparked by engagement in scholarly debate with advocates $[35,49]$ and opponents of MT [6,50], my perspective of MT has evolved over the past decade as new evidence has accumulated - most notably in terms of its dimensionality [e.g., 15,51]. I anticipate that my 
current perspective on MT will require refinements in the years to come as new data emerges alongside the diversification of research methods $[52,53]$. With this expectation in mind, I consider key substantive and methodological issues that may offer the greatest potential for refining and evolving the conceptualisation of MT.

The key priority for future work is to resolve the definitional issues regarding MT using guidelines for creating high-quality construct definitions [17-19]. There has been a tendency for MT researchers - including my colleagues and me [54] - to devote little time to this fundamental aspect of concept development, which in turn "triggers a sequence of events" that can undermine the construct validity enterprise in several ways (e.g., unrepresentative indicators, misspecified relations between constructs and measures) $[16, p$. 323]. The definition offered here provides an important first step, yet it requires enhancement through critical debate and empirical testing. As such, there is a need to reach expert consensus regarding the meaning, distinctiveness and usefulness of MT, perhaps through the use of a Delphi study of academic experts $[55,56]$ or a lexical analysis of lay person descriptions using social media platforms like Twitter and Facebook [57].

A renewed focus on definitional issues that fulfil expectations regarding construct clarity has the potential to reinvigorate MT research. However, the benefits of a clear definition can be undermined when there is incongruence between the conceptualisation and its operationalisation in research (see also supplementary material). For example, the 4Cs model of MT is operationalised primarily as a multidimensional construct through the MTQ48, yet there is also a unidimensional representation via the MTQ18 that is at odds with dimensionality proposed in the underpinning model [8]. To date, there has been little justification for the operationalisation of the 4Cs model of MT as both unidimensional and multidimensional in nature. As the modal conceptualisation of MT among researchers, such 
conflicting operationalisations only serve to thwart conceptual development and undermine the scientific legitimacy of MT.

There is also a need to devote additional attention to testing key conceptual propositions within definitions of MT. Two conceptual issues are of fundamental interest in this regard. First, as reliability and validity are properties of test scores rather than an instrument or tool itself, it is important for researchers to assess the hypothesised structure of a questionnaire in each study when sample size permits to provide an indication of the adequacy of the operationalisation of MT. For example, of the 39 papers published since 2014 that included at least 100 participants, only 17 studies (43.59\%) tested the factorial structure of the questionnaire employed to capture MT (see online supplementary material); of course, my work is not immune to this methodological criticism [23]. Second, most accounts regarding the stability of MT adopt a trait conceptualisation in which MT reflects consistencies in thinking, feeling and behaving across situations, contexts, and time [e.g., 8,14], yet are silent on the theoretical assumptions regarding its temporal consistency (e.g., justification for the temporal period between repeated assessments). For example, although the available test-retest data supports a trait conceptualisation of MT, there has been limited justification for the temporal period between repeated assessments, namely 2 or 7 days [27], 3 weeks [14,48], or 3 months [58-59]. I too have been guilty of this criticism in my work on the traitness of MT [15]. From a methodological standpoint, short temporal intervals are susceptible to carryover effects [60] and the use of test-retest reliability is limited to assessments of stability of test scores based on group means and variances. When intraindividual variations in MT are modelled using several assessments over a 12 week period, the evidence supports a state-like conceptualisation of MT [15]. Addressing the types of questions that underpin concept clarification requires a synergy between substance and method. 


\section{Conclusions}

237 Over the past two decades, MT has become a widespread area of investigation and 238 practice within sport and exercise psychology, with hundreds of studies and popular press

239 books published on the topic. However, the substantive contribution of these examinations of

240 MT have been muddied somewhat by imprecise definitions that vary in their fulfilment of

241 key expectations for construct clarity [17-19], and inconsistencies between conceptual

242 models and operationalisations via self-report tools. In this paper, I have offered a concise

243 overview of the field and in so doing underscored fundamental conceptual details that

244 provide a platform from which to clarify the meaning, distinctiveness, and usefulness of MT.

245 Much remains to be learned about MT, especially in terms of its dimensionality and stability.

246 My hope is that this paper will provide a stimulus for such work in the future. 


\section{References}

Papers of particular interest, published within the period of review, have been highlighted as:

*of special interest

**of outstanding interest

[1] Rusk RD, Waters LE. Tracing the size, reach, impact, and breadth of positive psychology. J Posit Psychol 2013, 8: 207-221.

[2] Loehr JE: Athletic excellence: Mental toughness training for sports. Plume; 1982.

[3] Luszki WA: Winning tennis through mental toughness. Everest House; 1982.

[4] Fourie S, Potgieter JR: The nature of mental toughness in sport. S Afr J Res Sport Ph 2011, 23: 63-72.

[5] Jones G, Hanton S, Connaughton D: What is this thing called mental toughness? An investigation of elite sport performers. J Appl Sport Psychol 2002, 14: 205-218.

** Seminal study in which 10 international performers provided their perspectives of the essential attributes of mental toughness in sport.

[6] Andersen MB: Who's mental, who's tough, and who's both? Mutton constructs dressed up as lamb. In Mental toughness in sport: Developments in theory and research. Edited by Gucciardi DF, Gordon S. Routledge; 2011: 69-88.

** First account of the critique's perspective on mental toughness. Andersen summarised several criticisms of the mental toughness literature that has helped shape recent work on this concept.

[7] Caddick N, Ryall, E: The social construction of 'mental toughness' - A fascistoid ideology? J Philos Sport 2012, 39: 137-154.

[8] Clough P, Earle K, Sewell, D: Mental toughness: The concept and its measurement. In Solutions in sport psychology. Edited by Cockerill. Thomson; 2002: 32-45.

** Original concept and measurement development paper regarding the 4Cs model of mental toughness and its operationalisation through the MTQ48 and MTQ18.

[9] Thelwell R, Weston N, Greenlees I: Defining and understanding mental toughness in soccer. J Appl Sport Psychol 2005, 17: 326-332.

[10] Gucciardi DF, Gordon S, Dimmock JA: Towards an understanding of mental toughness in Australian football. J Appl Sport Psychol 2008, 20: 261-281.

[11] Coulter T, Mallett CJ, Gucciardi DF: Understanding mental toughness in Australian soccer: Perceptions of players, parents, and coaches. J Sport Sci 2010, 28: 699-716.

[12] Middleton SC, Martin AJ, Marsh HW: Development and validation of the mental toughness inventory (MTI). In Mental toughness in sport: Developments in theory and research. Edited by Gucciardi DF, Gordon S. Routledge; 2011: 91-107.

[13] Clough P, Strycharczyk D: Developing mental toughness: Improving performance, wellbeing and positive behaviour in others. Kogan Page; 2012.

[14] Hardy L, Bell J, Beattie S: A neuropsychological model of mentally tough behaviour. J Pers 2014, 82: 69-81. 
** Multistudy report in which Hardy and colleagues drew from neuropsychological research and personality theory to show that individuals high in mental toughness are sensitive to punishment cues but insensitive to reward cues, which was explained through the early detection of threat.

[15] Gucciardi DF, Hanton S, Gordon S, Mallett CJ, Temby P: The concept of mental toughness: Tests of dimensionality, nomological network, and traitness. J Pers 2015, 83: 26-44.

** Multistudy report reconceptualised mental toughness to encompass subjective and objective goal progress, which challenged the status quo, and provided supportive evidence with students, employees, Special Forces candidates, and athletes.

[16] MacKenzie SB: The dangers of poor construct conceptualisation. J Acad Market Sci 2003, 31: 323-326.

[17] MacKenzie SB, Podsakoff PM, Podsakoff NP: Construct measurement and validation procedures in MIS and behavioural research: integrating new and existing techniques. MIS Quart 2011, 35: 293-334.

[18] Podsakoff PM, MacKenzie SB, Podsakoff NP. Recommendations for creating better concept definitions in the organizational, behavioural, and social sciences. Organ Res Methods 2016, 19:159-203.

* Provides guidance for researchers who are interested in defining and conceptualising a new concept or revising existing concepts.

[19] Suddaby R: Construct clarity in theories of management and organisation. Acad Manage Rev 2010, 35: 346 -357.

[20] Gucciardi DF, Hanton S: Mental toughness: critical reflections and future considerations. In Routledge international handbook of sport psychology. Edited by Schinke R, McGannon K, Smith B. Routledge, 2016; 439-448.

[21] Hobfoll SE: Social and psychological resources and adaptation. Rev Gen Psychol 2008, 307-324.

[22] Bell JJ, Hardy L, Beattie S: Enhancing mental toughness and performance under pressure in elite young cricketers: A 2-year longitudinal intervention. Sport Exerc Perform Psychol 2013, 2: 281-297.

** In this study, Bell and colleagues showed that repeated exposure to punishmentconditioned stimuli in the training environment was effective in enhancing mental toughness.

[23] Gucciardi DF: Mental toughness as a moderator of the intention-behaviour gap in the rehabilitation of knee pain. J Sci Med Sport 2016, 19: 454-458.

[24] Hannan TE, Moffitt RL, Neumann DL, Thomas PR: Applying the theory of planed behaviour to physical activity: the moderating role of mental toughness. J Sport Exerc Psychol 2015, 37: 514-522.

[25] Mahoney JW, Ntoumanis N, Mallett, C, Gucciardi D: The motivational antecedents of the development of mental toughness: a self-determination theory perspective. Int Rev Sport Exerc Psychol 2014, 7: 184-197. 
** Theoretical paper in which Mahoney and colleagues drew from self-determination theory to propose motivational antecedents of mental toughness, including striving surviving and thriving.

[26] Weinberg R, Butt J, \& Culp B: Coaches' views of mental toughness and how it is built. Int J Sport Exerc Psychol 2011, 9: 156-172.

[27] Madrigal L, Hamill S, Gill DL: Mind over matter: the development of the mental toughness scale (MTS). Sport Psychol 2013, 27:62-77.

[28] Kobasa SC: Stressful life events, personality, and health: an inquiry into hardiness. J Pers Soc Psychol 1979, 37: 1-11.

[29] Maddi SR: The story of hardiness: Twenty years of theorizing, research, and practice. Consult Psychol J 2002, 54: 173-185.

[30] Maddi SR: Hardiness as the existential courage to turn stresses into growth opportunities. In Motivation, consciousness, and self-regulation. Edited by Liontiev D. Nova Science, 2012; 127-138.

[31] Maddi SR: The courage and strategies of hardiness as helpful in growing despite major, disruptive stress. Am Psychol 2008, 63: 563-564.

[32] Eschleman KJ, Bowling NA, Alarcon GM. A meta-analytic examination of hardiness. Int J Stress Manage 2010, 17: 277-307.

[33] Hunsley J, Meyer GJ: The incremental validity of psychological testing and assessment: conceptual, methodological and statistical issues. Psychol Assessment 2003, 15: 446-455.

[34] Gucciardi DF, Hanton S, Mallett CJ: Progressing measurement in mental toughness: A case example of the Mental Toughness Questionnaire 48. Sport Exerc Perform Psychol 2012, 1: 194-214.

[35] Gucciardi DF, Hanton S, Mallett CJ: Progressing measurement in mental toughness: A response to Clough, Earle, Perry, and Crust. Sport Exerc Perform Psychol 2013, 2: $157-172$

[36] Masten AS. Global perspectives on resilience in children and youth. Child Dev 2014, 85: 6-20.

[37] Masten AS: Resilience in children threatened by extreme adversity: frameworks for research, practice, and translational synergy. Dev Psychopathol 23, 493-506.

[38] Bonanno GA, Romerso SA, Klein, SI: The temporal elements of psychological resilience: an integrative framework for the study of individuals, families, and communities. Psychol Inq 2015, 26: 139-169.

[39] Duckworth AL, Peterson C, Matthews MD, Kelly DR: Grit: passion and perseverance for long-term goals. J Pers Soc Psychol 2007, 92: 1087-1101.

[40] Duckworth AL, Gross JJ: Self-control and grit: Related but separable determinants of success. Curr Dir Psychol Sci 2014, 23: 319-325.

[41] Gucciardi DF, Peeling P, Ducker KJ, Dawson B: When the going gets tough: mental toughness and its relationship with behavioural perseverance. J Sci Med Sport 2016, 19: 81-86.

[42] McAdams DP: The psychological self as actor, agent, and author. Perspect Psychol Sci 2013, 8: 272-295.

[43] McAdams DP, Pals JL: A new Big Five: Fundamental principles for an integrative science of personality. Am Psychol 2006, 61: 204-217.

[44] Eskreis-Winkler L, Gross JJ, Duckworth AL: (in press). Grit: Sustained self-regulation in the service of superordinate goals. In Handbook of self-regulation: Research, theory and applications (3rd ed.). Edited by Vohs KD, Baumeister RF. Guilford; in press: 1-17. 
[45] Andersen MB, McCullagh P, Wilson G: But what do the numbers really tell us? Arbitrary metrics and effect size reporting in sport psychology research. J Sport Exerc Psychol 2007, 29: 664-672.

[46] Blanton H, Jaccard J: Arbitrary metrics in psychology. Am Psychol 2006, 61: 27-41. [47] Mahoney JW, Gucciardi DF, Ntoumanis N, Mallett CJ: Mental toughness in sport: motivational antecedents and associations with performance and psychological health. $J$ Sport Exerc Psychol 2014, 36: 281-292.

[48] Arthur CA, Fitzwater J, Hardy L, Beattie S, Bell J: Development and validation of a military training mental toughness inventory. Mil Psychol 2015, 27: 232-241.

[49] Clough P, Earle K, Perry JL, Crust L: Comment on "Progressing measurement in mental toughness: a case example of the mental toughness questionnaire 48 " by Gucciardi, Hanton, and Mallett (2012). Sport Exerc Perform Psychol 2013, 1: 283-287. [50] Gucciardi DF, Hanton S, Fleming S: Are mental toughness and mental health contradictory concepts in elite sport? a narrative review of theory and evidence. $J$ Sci Med Sport 2016. doi:10.1016/j.jsams.2016.08.006

[51] Gucciardi DF, Gordon S: Development and preliminary validation of the Cricket Mental Toughness Inventory (CMTI). J Sport Sci 2009, 27: 1293-1310.

[52] Coulter TJ, Mallett CJ, Singer JA: A subculture of mental toughness in an Australian football league club. Psychol Sport Exerc 2016, 22: 98-113.

* Example of the diversification in methodological approaches for the study of mental toughness in which the authors highlighted the importance of contextual norms within sport.

[53] Tibbert SJ, Andersen MB, Morris T: What a difference a "mentally toughening" year makes: the acculturation of a rookie. Psychol Sport Exerc 2015, 17: 68-78.

[54] Gucciardi DF, Gordon D, Dimmock JA: Development and preliminary validation of a mental toughness inventory for Australian football. Psychol Sport Exerc 2009, 10: 201209.

[55] Okoli C, Pawlowski SD: The Delphi method as a research tool: an example, design considerations and applications. Inform Manage 2004, 42:15-29.

[56] Diamond IR, Grant RC, Feldman BM, Pencharz PB, Ling SC, Moore AM, Wales PW: Defining consensus: a systematic review recommends methodologic criteria for reporting of Delphi studies. J Clin Epidemiol 2014, 67: 401-409.

[57] Landers RN, Brusso RC, Cavanaugh KJ, Collmus AB: A primer on theory-driven web scraping: automatic extraction of big data from the internet for use in psychological research. Psychol Methods in press. doi: 10.1037/met0000081

[58] Crust L, Nesti M, Littlewood M: A cross-sectional analysis of mental toughness in a professional football academy. Athlet Insigh 2010, 2: 165-174.

[59] Crust L, Nesti M, Littlewood M: Player and coach ratings of mental toughness in an elite association football academy. Athlet Insigh 2010, 2: 239-250.

[60] Roberts BW, Walton KE, Viechtbauer W: Patterns of mean-level change in personality traits across the life course: A meta-analysis of longitudinal studies. Psychol Bull 2006, 132: 1-25. 
Table 1. A chronology of primary definitions of mental toughness with the academic literature.

\begin{tabular}{|c|c|}
\hline Source & Definition \\
\hline $\begin{array}{l}\text { [5] Jones, Hanton, and } \\
\text { Connaughton }(2002, \mathrm{p} \text {. } \\
\text { 209) }\end{array}$ & $\begin{array}{l}\text { Mental toughness is having the natural or developed edge that enables you to: (i) generally, cope better than your opponents } \\
\text { with the many demands (competition, training, lifestyle) that sport places on a performer; (ii) specifically, be more consistent } \\
\text { and better than your opponents in remaining determined, focused, confident, and in control under pressure. }\end{array}$ \\
\hline $\begin{array}{l}\text { [8] Clough, Earle, and } \\
\text { Sewell (2002, p. 38) }\end{array}$ & $\begin{array}{l}\text { Mentally tough individuals tend to be sociable and outgoing; as they are able to remain calm and relaxed, they are } \\
\text { competitive in many situations and have lower anxiety levels than others. With a high sense of self-belief and an unshakeable } \\
\text { faith that they control their own destiny, these individuals can remain relatively unaffected by competition or adversity. }\end{array}$ \\
\hline $\begin{array}{l}\text { [9] Thelwell, Weston, } \\
\text { and Greenlees (2005) }\end{array}$ & $\begin{array}{l}\text { Mental toughness is having the natural or developed edge that enables you to: (i) always [emphasis added], cope better than } \\
\text { your opponents with the many demands (competition, training, lifestyle) that sport places on a performer; (ii) specifically, be } \\
\text { more consistent and better than your opponents in remaining determined, focused, confident, and in control under pressure. }\end{array}$ \\
\hline $\begin{array}{l}\text { [10] Gucciardi, Gordon } \\
\text { and Dimmock }(2008, p \text {. } \\
\text { 278) }\end{array}$ & $\begin{array}{l}\text { Mental toughness is a collection of values, attitudes, behaviours, and emotions that enable you to persevere and overcome any } \\
\text { obstacle, adversity, or pressure experienced, but also to maintain concentration and motivation when things are going well to } \\
\text { consistently achieve your goals. }\end{array}$ \\
\hline $\begin{array}{l}\text { [11] Coulter, Mallett, } \\
\text { and Gucciardi (2010, p. } \\
\text { 715) }\end{array}$ & $\begin{array}{l}\text { Mental toughness is the presence of some or the entire collection of experientially developed and inherent values, attitudes, } \\
\text { emotions, cognitions, and behaviours that influence the way in which an individual approaches, responds to, and appraises } \\
\text { both negatively and positively construed pressures, challenges, and adversities to consistently achieve his or her goals. }\end{array}$ \\
\hline $\begin{array}{l}\text { [12] Middleton, Martin } \\
\text { and Marsh (2011, p. 94) }\end{array}$ & Unshakeable perseverance and conviction towards some goal despite pressure or adversity \\
\hline $\begin{array}{l}\text { [13] Clough and } \\
\text { Strycharczyk (2012, p. } \\
\text { 1) }\end{array}$ & $\begin{array}{l}\text { The quality which determines in large part how people deal effectively with challenge, stressors and pressure...irrespective of } \\
\text { prevailing circumstances. }\end{array}$ \\
\hline $\begin{array}{l}\text { [14] Hardy, Bell and } \\
\text { Beattie }(2014, \text { p. } 70)\end{array}$ & Iental toughness is the ability to achieve personal goals in the face of pressure from a wide range of different stressors. \\
\hline $\begin{array}{l}\text { [15] Gucciardi, Hanton, } \\
\text { Gordon, Mallett, and } \\
\text { Temby (2015, p. 28) }\end{array}$ & $\begin{array}{l}\text { Mental toughness is a personal capacity to produce consistently high levels of subjective (e.g., personal goals or strivings) or } \\
\text { objective performance (e.g., sales, race time, GPA) despite everyday challenges and stressors as well as significant } \\
\text { adversities. }\end{array}$ \\
\hline
\end{tabular}


Running head: Mental toughness - supplementary material

\title{
Mental Toughness: Progress and Prospects
}

\author{
Daniel F. Gucciardi \\ School of Physiotherapy and Exercise Science, Curtin University
}

Author Notes

Address correspondence to Daniel Gucciardi, School of Physiotherapy and Exercise Science, Curtin University, GPO Box U1987, Perth, Australia, 6845. Email:

daniel.f.gucciardi@gmail.com

\section{Supplementary Material}




\section{Recent Trends in Mental Toughness}

A key aim for papers published in Current Opinions in Psychology is to provide readers with a synopsis of work published during the past two years. As such, I conducted an electronic search of five databases (Web of Science, Scopus, CINAHL Plus, SPORTDiscus, PsycINFO) on August $11^{\text {th }} 2016$ using the search term "mental* tough*". Articles that were accepted for publication or in press were identified using (ii) Google Scholar, (ii) manual searches of international journals where researchers have published work on mental toughness (e.g., The Sport Psychologist, Psychology of Sport and Exercise), and (iii) requested from researchers via the SPORTPSY Listserv on August $12^{\text {th }} 2016$. Papers were included as part of this review when they met the following criteria: (i) written in English, (ii) published in a peer-reviewed outlet, (iii) mental toughness was a key focus for the study or review, (iv) involved research or theory on humans, and (v) published 2014 onwards. Papers were excluded if the full text of the article could not be accessed. In total, 270 articles were retrieved. After duplicates were removed $(n=111)$, a review of abstracts and full texts (when the abstract was unclear) indicated that 75 papers met the inclusion criteria. Full citation details of these retained papers are noted below in Appendix A, with summaries of key methodological features of them included in the excel file in the online supplementary material.

From a methodological standpoint, a number of findings can be gleaned from this search. First, the majority of work during this period has involved cross-sectional snapshots of the study variables including an assessment of participants' mental toughness (49\%). Researchers have also made use of prospective designs (13\%) where the measurement of mental toughness as a predictor or outcome is temporally separated from other key variables by at least 2 weeks, and qualitative designs in which participants' experiences and perceptions of mental toughness are explored (12\%). Representing unique cases rather than 
general trends, it is encouraging to see the publication of conceptual papers that aim to clarify the theoretical features of mental toughness. For example, my colleagues and I drew from self-determination theory [1] to propose a tripartite model in which we emphasised the importance of understanding the dimensions of striving, surviving and thriving (i.e., what personal resources enable mentally tough individuals to do) for clarifying the conceptual theme of mental toughness [2]. The recent diversification in methodological approaches for the study of mental toughness [e.g., 3,4] is also encouraging because it has the potential to shed light on conceptual features that may not be gleaned through methods that employ standardised self-report questionnaires in which researchers impose their conceptualisation and operationalisation of mental toughness upon participants.

Second, it is pleasing to see that research on mental toughness is being conducted in a range of countries and cultures, which contrasts with an observation that Sandy Gordon and I made only 6 years ago [5]. Excluding review or conceptual papers, the majority of research on mental toughness over the past 2 years where new primary data was collected has involved British (30\%), American (19\%), Australian (19\%), and Swiss (14\%) participants. Nevertheless, research on mental toughness has received increased interest in other regions of the world including Asia (e.g., Malaysia, China), Europe (e.g., Denmark, Norway), Africa (e.g., Egypt, Tunisia), and the Middle East (e.g., Iran). This renewed interested in mental toughness from a diverse group of researchers has the potential to enhance the quality of research in this area and therefore evolve theoretical perspectives on this construct. For example, my colleagues and I examined the cross-cultural invariance of the mental toughness inventory [6] as self-reported by Australian, Malaysia, and Chinese athletes [7]. We found that a unidimensional structure of mental toughness generalized across these three cultural groups. However, there were subtle yet substantively meaningful differences on a selection of item means. These findings suggest the need to examine culturally-salient aspects of mental 
toughness in future measurement work, which could shed light on the boundary conditions of this construct.

Third, in 58 of the 70 empirical papers, mental toughness was measured using self- or informant-reports. The following scales were most commonly used to measure mental toughness: the MTQ48 $(\mathrm{n}=17)$, SMTQ $(\mathrm{n}=10)$, MTQ18 $(\mathrm{n}=8)$, MTI $(\mathrm{n}=7)$, a bespoke measure for the purposes of the study $(n=5)$, PPI $(n=4)$, and PPI-A $(n=2)$. Consistent with our recent observation [8], these data indicate that the MTQ48 and its shortened version (MTQ18) remain the tool of choice for most researchers interested in mental toughness. However, there are inconsistencies in the ways by which researchers operationalise models of mental toughness through self-report instruments. For example, both the MTQ48 and MTQ18 are underpinned by the 4Cs model of mental toughness, yet they differ in their operationalisation of the dimensionality of the concept; whereas a multidimensional perspective is captured by the MTQ48, a unidimensional concept is assessed by the MTQ18 [9]. A global mental toughness score is often used alongside the sub-components of the MTQ48 [e.g., 10,11] and SMTQ [e.g., 12,13], yet the bi-factor structure of these tools has not yet received support nor been tested for its validity [14]. In other cases, the theorised multidimensionality of mental toughness is captured via a global factor only [e.g., 15,16] without any evidence to support the higher-order structure of the tool in which a second-order factor explains the variance among a set of lower-order factors [14]. It is important for the conceptual evolution and scientific integrity of mental toughness that there is congruence between the conceptual model and its operationalisation in future research. 


\section{References}

1. Deci EL, Ryan RM: The 'what' and 'why' of goal pursuits: human needs and the self-determination of behaviour. Psychol Inq 2000, 11: 227-268.

2. Mahoney JW, Ntoumanis N, Mallett, C, Gucciardi D: The motivational antecedents of the development of mental toughness: a self-determination theory perspective. Int Rev Sport Exerc Psychol 2014, 7: 184-197.

3. Coulter TJ, Mallett CJ, Singer JA: A subculture of mental toughness in an Australian football league club. Psychol Sport Exerc 2016, 22: 98-113.

4. Tibbert SJ, Andersen MB, Morris T: What a difference a "mentally toughening" year makes: the acculturation of a rookie. Psychol Sport Exerc 2015, 17: 68-78.

5. Gucciardi DF, Gordon: Mental toughness in sport: past, present and future. In Mental Toughness in Sport: Developments in Theory and Research. Edited by Gucciardi DF, Gordon S. Routledge; 2011: 223-251.

6. Gucciardi DF, Hanton S, Gordon S, Mallett CJ, Temby P: The concept of mental toughness: tests of dimensionality, nomological network, and traitness. J Pers 2015, 83: 26-44.

7. Gucciardi DF, Zhang C-Q, Ponnusamy V, Si G, Stenling A: Cross-cultural invariance of the Mental Toughness Inventory among Australian, Chinese, and Malaysian athletes: a Bayesian estimation approach. J Sport Exerc Psychol 2016. doi: 10.1123/jsep.2015-0320

8. Gucciardi DF, Hanton S, Mallett CJ: Progressing measurement in mental toughness: A case example of the Mental Toughness Questionnaire 48. Sport Exerc Perform Psychol 2012, 1: 194-214.

9. Clough P, Earle K, Sewell, D: Mental toughness: The concept and its measurement. In Solutions in sport psychology. Edited by Cockerill. Thomson; 2002: 32-45.

10. Brand S, Kalak N, Gerber M, Clough PJ, Lemola S, Pühse U, Holsboer-Trachsler E: During early and mid-adolescence, greater mental toughness is related to increased sleep quality and quality of life. J Health Psychology 2016, 21: 905-915. doi: $10.1177 / 1359105314542816$

11. Crust L, Earle K, Perry J, Earle F, Clough A, Clough PJ: Mental toughness in higher education: relationships with achievement and progression in first-year university sports students. Pers Indiv Differ 2014, 69: 87-91. doi: 10.1016/j.paid.2014.05.016

12. Cowden RG, Meyer-Weitz A: Mental toughness in South African competitive tennis: biographical and sport participation differences. Int J Sport Exerc Psychol 2016, 14: 152-167. doi: 10.1080/1612197X.2015.1121509

13. Meggs J, Ditzfeld C, Golby J: Self-organisation and mental toughness in sport. $J$ Sport Sci 2014, 32: 101-109. doi: 10.1080/02640414.2013.812230

14. Chen FF, Hayes A, Carver CS, Laurenceau JP, Zhang Z: Modeling general and specific variance in multifaced constructs: A comparison of the bifactor model to other approaches. J Pers 2012, 80: 219-251.

15. Brand S, Gerber M, Kalak N, Kirov R, Lemola S, Clough PJ, Pühse U, HolsboerTrachsler E: "Sleep well, our tough heroes!" - in adolescence, greater mental toughness is related to better sleep schedules. Behav Sleep Med 2014, 12: 444-454.

16. Jackman PC, Swann C, Crust L: Exploring athletes' perceptions of the relationship between mental toughness and dispositional flow in sport. Psychol Sport Exerc 2016, 27: 56-65. 
Appendix A - Reference Details of Retained Papers from Systematic Review

1. Andrews $\mathrm{P}$, Chen MA: Gender differences in mental toughness and coping with injury in runners. $J$ Athl Enhanc 2014, 3:6. doi: 10.4172/2324-9080.1000183

2. Anthony DA, Gucciardi DF, Gordon S: A meta-study of qualitative research on mental toughness development. Int Rev Sport Exercise Psychol 2016, 9: 160-190.

3. Arthur CA, Fitzwater J, Hardy L, Beattie S, Bell J: Development and validation of a military training mental toughness inventory. Mil Psychol 2015, 27: 232-241. doi: 10.1037/mil0000074

4. Atito A, Abdelaty A: Psychological predictors of sports injuries among Egyptian elite players. Ovidus University Annals, Series Physical Education and Sport Science, Movement and Health 2016, 16: 25-32.

5. Bahmani DS, Gerber M, Kalak N, Lemola S, Clough PJ, Calabrese P, Shaygannejad V, Pühse U, Holsboer-Trachsler E, Brand S: Mental toughness, sleep disturbances, and physical activity in patients with multiple sclerosis compared to healthy adolescents and young adults. Neuropsychiatr Dis Treat 2016, 12: 1571-1579. doi: 10.2147/NDT.S111208

6. Bauman NJ: The stigma of mental health in athletes: are mental toughness and mental health seen as contradictory in elite sport? Br J Sports Med 2016, 50: 135 136. doi:10.1136/bjsports-2015-095570

7. Brand S, Gerber M, Kalak N, Kirov R, Lemola S, Clough PJ, Pühse U, HolsboerTrachsler E: Adolescents with greater mental toughness show higher sleep efficiency, more deep sleep and fewer awakenings after sleep onset. J Adolescen Health 2014, 54: 109-113. doi: 10.1016/j.jadohealth.2013.07.017

8. Brand S, Gerber M, Kalak N, Kirov R, Lemola S, Clough PJ, Pühse U, HolsboerTrachsler E: "Sleep well, our tough heroes!" - in adolescence, greater mental toughness is related to better sleep schedules. Behav Sleep Med 2014, 12: 444-454. doi: 10.1080/15402002.2013.825839

9. Brand S, Hatzinger M, Stadler C, Bolten M, von Wyl A, Perren S, von Klitzing K, Stadelmann S, Holsboer-Trachsler E: Does objectively assessed sleep at five years predicte sleep and psychological functioning at 14 years? Hmm, yes and no! $J$ Psychiatr Res 2015, 60: 148-155. doi: 10.1016/j.jpsychires.2014.10.007

10. Brand S, Kalak N, Gerber M, Clough PJ, Lemola S, Bahmani DS, Pühse U, HolsboerTrachsler E: During early to mid adolescence, moderate to vigorous physical activity is associated with restoring sleep, psychological functioning, mental toughness and male gender. J Sport Sci 2016. doi: 10.1080/02640414.2016.1167936

11. Brand S, Kalak N, Gerber M, Clough PJ, Lemola S, Pühse U, Holsboer-Trachsler E: During early and mid-adolescence, greater mental toughness is related to increased sleep quality and quality of life. J Health Psychology 2016, 21: 905-915. doi: 10.1177/1359105314542816

12. Brand S, Kirov R, Kalak N, Gerber M, Pühse U, Lemola S, Correll CU, Cortese S, Meyer T, Holsboer-Trachsler E: Perfectionism related to self-reported insomnia severity, but not when controlled for stress and emotion regulation. Neuropsychiatr Dis Treat 2015, 11: 263-271. doi: 10.2147/NDT.S74905

13. Breslin G, Murphy MH, Kremer, McClean C, Davidson G: Providing sport psychology support to an athlete in a unique, ultra-endurance event. $J$ Sport Psychol Action 2014, 5: 59-72. doi: 10.1080/21520704.2014.892911

14. Cook C, Crust L, Littlewood M, Nesti M, Allen-Collinson J: 'What it takes': perceptions of mental toughness and its development in an English premier 
league soccer academy. Qual Res Sport Exerc Health 2014, 6: 329-347. doi: 10.1080/2159676X.2013.857708

15. Coulter TJ, Mallett CJ, Singer JA: A subculture of mental toughness in an Australian football league club. Psychol Sport Exerc 2016, 22: 98-113. doi: 10.1016/j.psychsport.2015.06.007

16. Cowden RG, Meyer-Weitz A: Mental toughness in South African competitive tennis: biographical and sport participation differences. Int J Sport Exerc Psychol 2016, 14: 152-167. doi: 10.1080/1612197X.2015.1121509

17. Cowden RG: Competitive performance correlates of mental toughness in tennis: a preliminary analysis. Percept Motor Skill 2016, 123: 341-360. doi: $10.1177 / 0031512516659902$

18. Cowden RG, Anshel MH, Fuller DK: Comparing athletes' and their coaches' perceptions of athletes' mental toughness among elite tennis players. J Sport Behav 2014, 37: 221-235.

19. Cowden RG, Fuller DK, Anshel MH: Psychological predictors of mental toughness in elite tennis: an exploratory study in learned resourcefulness and competitive trait anxiety. Percept Motor Skill 2014, 119: 1-18. doi: 10.2466/30.PMS.119c27z0

20. Cowden RG, Meyer-Weitz A, Asante KO: Mental toughness in competitive tennis: relationships with resilience and stress. Front Psychol 2016, 7: 320. doi: 10.3389/fpsyg.2016.00320

21. Crust L, Earle K, Perry J, Earle F, Clough A, Clough PJ: Mental toughness in higher education: relationships with achievement and progression in first-year university sports students. Pers Indiv Differ 2014, 69: 87-91. doi: 10.1016/j.paid.2014.05.016

22. Crust L, Swann C, Allen-Collinson J, Breckon J, Weinberg R: A phenomenological exploration of exercise mental toughness: perceptions of exercise leaders and regular exercisers. Qual Res Sport Exerc Health 2014, 6: 441-461. doi: 10.1080/2159676X.2014.901986

23. Delaney PF, Goldman JA, King JS, Nelson-Gray RO: Mental toughness, reinforcement sensitivity theory, and the five-factor model: personality and directed forgetting. Pers Indiv Differ 2015, 83: 180-184. doi: 10.1016/j.paid.2015.04.020

24. Diment GM: Mental toughness in soccer: a behavioural analysis. J Sport Behav 2014, 37: 317-332.

25. Gayatri P, Saon S, Gireesh P: Comparative study of mental toughness between national and interuniversity level female hockey players. Int J Sports Sci Fitness 2016, 6: 57-69.

26. Gerber M, Feldmeth AK, Lang C, Brand S, Elliot C, Holsboer-Trachsler E, Pühse U: The relationship between mental toughness, stress, and burnout among adolescents: a longitudinal study with Swiss vocational students. Psychol Rep 2015, 117: 703-723. doi: 10.2466/14.02.PR0.117c29z6

27. Gerber M, Lang C, Feldmet AK, Elliot C, Brand S, Holsboer-Trachsler E, Pühse U: Burnout and mental health in Swiss vocational students: the moderating role of physical activity. J Res Adolescence 2015, 25: 63-74. doi: 10.1111/jora.12097

28. Gucciardi DF, Hanton S, Gordon S, Mallet CJ, Temby P: The concept of mental toughness: tests of dimensionality, nomological network, and traitness. J Pers 2015, 83: 26-44. doi: 10.1111/jopy.12079

29. Gucciardi DF: Mental toughness as a moderator of the intention-behaviour gap in the rehabilitation of knee pain. J Sci Med Sport 2016, 19: 454-458. doi:

10.1016/j.jsams.2015.06.010 
30. Gucciardi DF, Jackson B, Hanton S, Reid M: Motivational correlates of mentally tough behaviours in tennis. J Sci Med Sport 2015, 18: 67-71. doi: 10.1016/j.jsams.2013.11.009

31. Gucciardi DF, Jackson B, Hodge K, Anthony DA, Brooke LE: Implicit theories of mental toughness: relations with cognitive, motivational, and behavioural correlates. Sport Exerc Perform Psychol 2015, 4: 100-112. doi: 10.1037/spy0000024

32. Gucciardi DF, Peeling P, Ducker KJ, Dawson B: When the going gets tough: mental toughness and its relationship with behavioural perseverance. J Sci Med Sport 2016, 19: 81-86. doi: 10.1016/j.jsams.2014.12.005

33. Gucciardi DF, Hanton S, Fleming S: Are mental toughness and mental health contradictory concepts in elite sport? a narrative review of theory and evidence. J Sci Med Sport 2016. doi:10.1016/j.jsams.2016.08.006

34. Gucciardi DF, Zhang C-Q, Ponnusamy V, Si G, Stenling A: Cross-cultural invariance of the Mental Toughness Inventory among Australian, Chinese, and Malaysian athletes: a Bayesian estimation approach. J Sport Exerc Psychol 2016. doi: 10.1123/jsep.2015-0320

35. Guillén F, Laborde S: Higher-order structure of mental toughness and the analysis of latent mean differences between athletes from 34 disciplines and nonathletes. Pers Indiv Differ 2014, 60: 30-35. doi: 10.1016/j.paid.2013.11.019

36. Hagag H, Ali M: The relationship between mental toughness and results of the Egyptian fencing team at the $9^{\text {th }}$ all-Africa games. Ovidus University Annals, Series Physical Education and Sport Science, Movement and Health 2014, 14: 85-90.

37. Hannan TE, Moffitt RL, Neumann DL, Thomas PR: Applying the theory of planed behaviour to physical activity: the moderating role of mental toughness. $J$ Sport Exerc Psychol 2015, 37: 514-522. doi: 10.1123/jsep.2015-0074

38. Hardy L, Bell J, Beattie S: A neuropsychological model of mentally tough behaviour. J Pers 2014, 82: 69-81. doi: 10.1111/jopy.12034

39. Hardy JH, Imose RA, Day EA: Relating trait and domain mental toughness to complex task learning. Pers Individ Differ 2014, 68: 59-64. doi: 10.1016/j.paid.2014.04.011

40. Haugen T, Reinboth M, Hetlelid KJ, Peters DM, Høigaard R: Mental toughness moderates social loafing in cycle time-trial performance. Res Q Exerc Sport 2016. doi: 10.1080/02701367.2016.1149144

41. Jackman PC, Swann C, Crust L: Exploring athletes' perceptions of the relationship between mental toughness and dispositional flow in sport. Psychol Sport Exerc 2016, 27: 56-65. doi: 10.1016/j.psychsport.2016.07.007

42. Jaeschke A-M, Sachs M, Dieffenbach K: Ultramarathon runners' perceptions of mental toughness: a qualitative inquiry. Sport Psychol 2016. doi: 10.1123/tsp.2014-0153

43. Jin L, Wang CDC: International students' attachment and psychological wellbeing; the mediation role of mental toughness. Couns Psychol 2016. doi: 10.1080/09515070.2016.1211510

44. Knust S, LaGuerre K, Wrisberg C, King C, Berggrun N: Preliminary evidence for a relationship between mental toughness and quality of life for NCAA division-I student-athletes. Athlet Insight 2014, 6: 173-184.

45. Madrigal L, Gill DL: Psychological responses of division I female athletes throughout injury recovery: a case study approach. J Clin Sport Psychol 2014, 8: 276-298. doi: 10.1123/jcsp.2014-0034 
46. Mahoney JW, Gucciardi DF, Ntoumanis N, Mallett CJ: Adolescent performers' perspectives on mental toughness and its development: the utility of the biolecological model. Sport Psychol 2014, 28: 233-244. doi: 10.1123/tsp.2013-0050

47. Mahoney JW, Gucciardi DF, Ntoumanis N, Mallett CJ: Mental toughness in sport: motivational antecedents and associations with performance and psychological health. J Sport Exerc Psychol 2014, 36: 281-292. doi: 10.1123/jsep.2013-0260

48. Mahoney JW, Ntoumanis N, Mallett, C, Gucciardi D: The motivational antecedents of the development of mental toughness: a self-determination theory perspective. Int Rev Sport Exerc Psychol 2014, 7: 184-197. doi: 10.1080/1750984X.2014.925951

49. Mahoney JW, Ntoumanis N, Gucciardi DF, Mallett CJ, Stebbings J: Implementing an autonomy-supportive intervention to develop mental toughness in adolescent rowers. J Appl Sport Psychol 2016, 28: 199-215. doi: 10.1080/10413200.2015.1101030

50. McGeown SP, St Clair-Thompson H, Clough P: The study of non-cognitive attributes in education: proposing the mental toughness framework. Educ Rev 2016, 68: 96-113. doi: 10.1080/00131911.2015.1008408

51. Meggs J, Ditzfeld C, Golby J: Self-organisation and mental toughness in sport. $J$ Sport Sci 2014, 32: 101-109. doi: 10.1080/02640414.2013.812230

52. Mostafa M: The effect of mental toughness training on elite athlete self-concept and record level of 50m crawl swimming for swimmers. Ovidus University Annals, Series Physical Education and Sport Science, Movement and Health 2015, 15: 468473.

53. Nicholls AR, Morley D, Perry JL: Mentally tough athletes are more aware of unsupportive coaching behaviours: perceptions of coach behaviour, motivational climate, and mental toughness in sport. Int J Sports Sci Coach 2016, 11: 171-181. doi: $10.1177 / 1747954116636714$

54. Nicholls AR, Perry JL, Jones L, Sanctuary C, Carson F, Clough PJ: The mediating role of mental toughness in sport. J Sports Med Phys Fitness 2015, 55: 824-834.

55. Onley M, Veselka L, Schermer JA, Vernon PA: Survival of the scheming: a genetically informed link between the dark triad and mental toughness. Twin Res Hum Genet 2014, 16: 1087-1095. doi:10.1017/thg.2013.66

56. Owusu-Sekyere F, Gervis M: In the pursuit of mental toughness: is creating mentally tough players a disguise for emotional abuse? Int J Coach Sci 2016, 10: 3-23.

57. Perry JL, Nicholls AR, Clough PJ, Crust L: Assessing model fit: caveats and recommendations for confirmatory factor analysis and exploratory structural equation modelling. Meas Phys Educ Exerc Sci 2015, 19:12-21. doi: 10.1080/1091367X.2014.952370

58. Petrie TA, Deiters J, Harmison RJ: Mental toughness, social support, and athletic identity; moderators of the life stress-injury relationship in collegiate football players. Sport Exerc Perform Psychol 2014, 3: 13-27. doi: 10.1037/a0032698

59. Philippe RA, Sagar SS, Gerber M, Hauw D: Players' perceptions of coaches' contributions to their mental toughness. Int J Coach Sci 2016, 10: 37-51.

60. Ragab M. The effects of mental toughness training on athletic coping skills and shooting effectiveness for national handball players. Ovidus University Annals, Series Physical Education and Sport Science, Movement and Health 2015, 15: 431435.

61. Sabouri S, Gerber M, Bahmani DS, Lemola S, Clough PJ, Kalak N, Shamsi M, Holsboer-Trachsler E, Brand S: Examining dark triad traits in relation to mental 
toughness and physical activity in young adults. Neuropsychiatr Dis Treat 2016, 12: 229-235. doi: 10.2147/NDT.S97267

62. Schaefer J, Vella SA, Allen MS, Magee CA: Competition anxiety, motivation, and mental toughness in golf. $J$ Appl Sport Psychol 2016, 28: 309-320. doi: 10.1080/10413200.2016.1162219

63. Slack LA, Butt J, Maynard IW, Olusoga P: Understanding mental toughness in elite football officiating: perceptions of English premier league referees. Sport Exer Psychol Rev 2014, 10: 4-24.

64. Slack LA, Maynard IW, Butt J, Olusoga P: An evaluation of a mental toughness education and training program for early-career English football league referees. Sport Psychol 2015, 29: 237-257. doi: 10.1123/tsp.2014-0015

65. Slimani M, Miarka B, Briki W, Cheour F: Comparison of mental toughness and power test performances in high-level kickboxers by competitive success. Asian J Sports Med 2016. doi: 10.5812/asjsm.30840

66. Solomon GB: Mental toughness among college athletes. J Appl Sports Sci 2015, 5: 171-175.

67. St Clair-Thompson H, Bugler M, Robinson J, Clough P, McGeown SP, Perry J: Mental toughness in education: exploring relationships with attainment, attendance, behaviour and peer relationships. Educ Psychol 2015, 35: 886-907. doi: 10.1080/01443410.2014.895294

68. St Clair-Thompson H, Giles R, McGeown SP, Putwain D, Clough P, Perry J: Mental toughness and transitions to high school and to undergraduate study. Educ Psychol 2016. doi: 10.1080/01443410.2016.1184746

69. Stamp E, Crust L, Swann C, Perry J, Clough P, Marchant D: Relationships between mental toughness and psychological wellbeing in undergraduate students. Pers Indiv Differ 2015, 75: 170-174. doi: 10.1016/j.paid.2014.11.038

70. Stonkus MA, Royal KD: Further validation of the inventory of mental toughness factors in sport (IMTF-S). Int J Psychol Stud 2015, 7: 35-45. doi:10.5539/ijps.v7n3p35

71. Subramanyam V: The relationship among self confidence, negative energy control, attentional control, visualisation/imagery control, motivational level, positive energy and attitude control in elite national athletes of India: a correlational study. Int J Sports Sci Fitness 2014, 4: 177-184.

72. Tavrah N, Nejad FA, Alipour O: Effect of emotional intelligence on mental toughness among the study athletes (a case study: students from Islamic Azad university of Karaj). Int J Bus 2016, 10: 1203-1206. doi: 10.3923/ibm.2016.1203.1206

73. Tibbert SJ, Andersen MB, Morris T: What a difference a "mentally toughening" year makes: the acculturation of a rookie. Psychol Sport Exerc 2015, 17: 68-78. doi: 10.1016/j.psychsport.2014.10.007

74. Weinberg R, Freysinger V, Mellano K, Brookhouse E: Building mental toughness: perceptions of sport psychologists. Sport Psychol 2016. doi: 10.1123/tsp.2015-0090

75. Wieser R, Thiel H: A survey of "mental hardiness" and "mental toughness" in professional male football players. Chiropr Manual Ther 2016, 22: 17. doi: 10.1186/2045-709X-22-17 